\title{
SISTEM INFORMASI BERBASIS WEB PEMANTAUAN KEGIATAN PRAKTIKUM DI LABORATORIUM TEKNIK INDUSTRI
}

\author{
Hanindhiya Ika Septiana(1), Dessyanto Boedi(2), Oliver S. Simanjuntak ${ }^{(3)}$ \\ Program Studi Teknik Informatika UPN "Veteran" Yogyakarta \\ Jl. Babarsari no 2 Tambakbayan 55281 Yogyakarta Telp (0274)-485323 \\ e-mail : hanindhiya.ika@gmail.com ${ }^{(1)}$, dess95@gmail.com ${ }^{(2)}$, oliver.simanjuntak@upnyk.ac.id(3)
}

\begin{abstract}
In practicum activities, laboratory assistants input data in the form of minutes, input values, input presences, and report preparation in an excel form. When the assistant wants to see the development of a student, then the assistant must open excel data one by one and look for the student's name or number and then collect the scores from previous meetings starting from the quiz value, assignment value, report value, project value, and response then check whether the student experiences an increase or decrease in the lab. With a large number of students, of course, the assistant will encounter difficulties if you have to find students one by one while the excel data is not small. The solution provided is to create a web-based system as the application of smart labs to monitor the development of student grades in the campus laboratory environment. By using a web-based system, laboratory assistants and lecturers will be facilitated to recapitulate student grades and monitor students as well as input values or calculate the final grades of students. The study uses the Waterfall method as a method of developing systems and research methodologies by conducting observations, interviews, and literature. The results obtained are that the system can display values in the form of a practicum value report that has been calculated using assessment weights and graphs that show the development of values at each meeting with different value categories.
\end{abstract}

\section{Keywords : Information System, Practicum, Smart Lab}

\begin{abstract}
Abstrak
Pada kegiatan praktikum, asisten laboratorium melakukan penginputan data berupa berita acara, input nilai, input presensi dan pembuatan laporan ke dalam dokumen berupa excel. Ketika asisten ingin melihat perkembangan seorang mahasiswa, maka asisten harus membuka data excel satu persatu dan mencari nama atau nomor mahasiswa tersebut lalu mengumpulkan nilai dari berbagai pertemuan sebelumnya mulai dari nilai kuis, nilai tugas, nilai laporan, nilai projek dan responsi lalu mengecek apakah mahasiswa tersebut mengalami penaikan atau penurunan pada praktikum tersebut. Dengan jumlah mahasiswa yang banyak tentunya asisten akan mengalami kesulitan jika harus mencari mahasiswa satu persatu sementara data excel tidaklah sedikit. Solusi yang diberikan adalah dengan membuat sistem berbasis web sebagai penerapan smart lab untuk memantau perkembangan nilai mahasiswa di lingkungan laboratorium kampus. Dengan menggunakan sistem berbasis web, maka asisten laboratorium dan dosen pengampu akan dimudahkan dalam merekap nilai mahasiswa dan memantau mahasiswa praktikan serta menginput nilai ataupun menghitung nilai akhir dari mahasiswa praktikan. Penelitian menggunakan metode Waterfall sebagai metode pengembangan sistem dan metodologi penelitian dengan melakukan observasi, wawancara dan studi pustaka. Hasil yang didapatkan adalah sistem dapat menampilkan nilai dalam bentuk laporan nilai praktikum yang sudah dihitung menggunakan bobot penilaian dan grafik yang menampilkan perkembangan nilai di setiap pertemuan dengan kategori nilai yang berbeda-beda.
\end{abstract}

Kata Kunci : Sistem Informasi, Praktikum, Smart Lab

\section{PENDAhULUAN}

Pada kegiatan praktikum, asisten laboratorium melakukan penginputan data berupa berita acara, input nilai, input presensi dan pembuatan laporan ke dalam dokumen berupa excel. Ketika asisten ingin melihat perkembangan seorang mahasiswa, maka asisten harus membuka data excel satu - persatu dan mencari nama atau nomor induk mahasiswa tersebut dan mengumpulkan nilai dari pertemuan - pertemuan sebelumnya mulai dari nilai kuis, nilai tugas, nilai laporan, nilai projek dan responsi lalu mengecek apakah mahasiswa tersebut 
mengalami penaikan atau penurunan pada praktikum tersebut. Dengan jumlah mahasiswa yang banyak tentunya asisten akan mengalami kesulitan jika harus mencari mahasiswa satu persatu sementara data excel tidaklah sedikit sehingga tidak dapat dipungkiri bahwa sistem yang lama mau tidak mau harus pindah ke smart lab.

Smart Lab dimaksudkan untuk membuat laboratorium menjadi lingkungan pendidikan yang lebih baik bagi mahasiswa dan instruktur. Dalam instruktur komputer Smart Lab disediakan informasi tentang kemajuan setiap siswa ketika mereka melakukan tugas pemrograman, memungkinkan instruktur untuk dengan mudah menanggapi masalah siswa dan menilai keseluruhan kemajuan kelas (Alammary, Carbone, \& Sheard, 2012).

Penelitian terkait yang sudah ada sebelumnya dilakukan oleh (Alammary et al., 2012) dengan judul "Implementation of a Smart Lab for Teachers of Novice Programmers". Penelitian ini menjelaskan tentang smart lab yang dimaksudkan untuk membuat laboratorium menjadi lingkungan pendidikan yang lebih baik bagi mahasiswa dan asisten. Dalam smart lab disediakan informasi tentang kemajuan setiap mahasiswa ketika mereka melakukan tugas praktikum sehingga memungkinkan asisten dengan mudah memberi penilaian kepada praktikan. Hasil dari penelitian ini berupa smart lab yang dapat meningkatkan pemahaman asisten terhadap masalah nilai pada mahasiswa yang memungkinkan asisten untuk memberikan nilai yang tepat terhadap praktikan.

Dengan semua permasalahan yang telah dijelaskan mulai dari masalah sulitnya asisten dan mahasiswa melihat rekap nilai, sulitnya asisten mencari data mahasiswa, sulitnya dosen memantau praktikum dan berbagai kekurangan yang ada pada penelitian sebelumnya, maka solusi yang diberikan adalah dengan membuat sistem berbasis web sebagai penerapan smart lab untuk memantau perkembangan nilai mahasiswa di lingkungan laboratorium program studi. Dengan menggunakan sistem berbasis web, maka asisten laboratorium akan dimudahkan dalam merekap nilai mahasiswa dan memantau mahasiswa praktikan serta menginput nilai ataupun menghitung nilai akhir dari praktikan.

\section{METODE PENELITIAN}

Dalam penelitian ini, metodologi penelitian dilakukan dengan cara observasi, wawancara dan studi pustaka. Observasi dilakukan di Program Studi sebagai pendukung dalam pembuatan sistem. Hasil observasi berupa data - data mahasiswa dan data mata kuliah praktikum, data plug, data asisten laboratorium. Wawancara dilakukan dengan beberapa asisten laboratorium. Adapun hal - hal yang ditanyakan sebagai berikut : 1) Sistem penilaian praktikum di Prodi ,2) Jumlah asisten laboratorium, 3) Jumlah plug pada setiap praktikum, 4) Jumlah mahasiswa praktikum pada setiap plug, 5) Fasilitas yang dibutuhkan jika ada sistem baru. Tahap studi pustaka dilakukan membantu pembuatan penelitian dan sistem dengan membaca teori-teori pendukung penelitian. Teori menganai sistem informasi dan sistem informasi manajemen laboratorium, teori mengenai pembuatan uml dan sebagainya. Selain itu juga, membaca dan menganalisis penelitian yang pernah dilakukan sebelumnya sebagai referensi untuk pembuatan sistem. Referensi tersebut didapatkan melalui jurnal online yang ada pada google scholar, situs jurnal online kampus maupun skripsi di perpustakaan dan penelitian lainnya.

Pengembangan sistem menggunakan Waterfall. Waterfall adalah salah satu model SDLC yang mempunya ciri khas pengerjaan yaitu setiap fase dalam waterfall harus diselesaikan terlebih dahulu sebelum melanjutkan fase berikutnya, yang dapat dijelaskan sebagai berikut: 1) Analisa Kebutuhan. Pada langkah ini dilakukan pengumpulan kebutuhan untuk pengembangan sistem melalui wawancara kepada pengguna sistem. Pengumpulan data juga dilakukan pada tahap termasuk menganalisa kebutuhan perangkat lunak dan perangkat keras yang mendukung pembuatan sistem. 2) Desain Sistem. Desain sistem bertujuan untuk mendapatkan gambaran mengenai sistem yang akan dibuat, alur data yang masuk dan keluar sistem, selain itu dapat terlihat data apa saja yang terlibat dalam sistem dan perancangan tampilan sistem. 3) Penulisan Kode Program. Setelah perancangan dibentuk, maka selanjutnya di implementasikan menggunakan bahasa pemrograman yaitu php dengan bantuan netbeans IDE 8.1 dan penyimpanan data menggunakan phpmyadmin. 
3. ANALISIS DAN PERANCANGAN

\subsection{Arsitektur Sistem}

Sistem Informasi Kegiatan Praktikum dibuat bertujuan untuk memudahkan asisten dan dosen dalam memantau kegiatan praktikum berlangsung dan khusus untuk asisten dapat menginputkan nilai dan melihat rata- rata nilai dan hasil nilai akhir secara langsung dalam bentuk laporan dan grafik, selain itu mahasiswa juga mendapatkan pengumuman dari asisten laboratorium dan informasi penilaian.

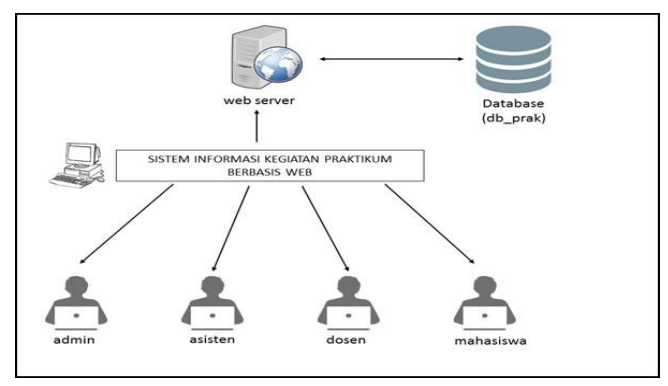

Gambar 1. Arsitektur Sistem

\subsection{Perancangan Sistem}

Pada perancangan sistem pada Sistem Informasi Kegiatan Praktikum berbasis web menggunakan DFD. DFD pada sistem tersebut dibagi menjadi tiga level yaitu DFD level 0, DFD level 1 dan DFD level 2.

\subsubsection{DFD Level 0}

Pada DFD level 0 terdapat empat entitas yaitu admin, asisten laboratorium, mahasiswa dan dosen. Pada keempat entitas baik admin, asisten, maupun dosen melakukan login dan registrasi. Akan tetapi, pada entitas mahasiswa hanya melakukan login.

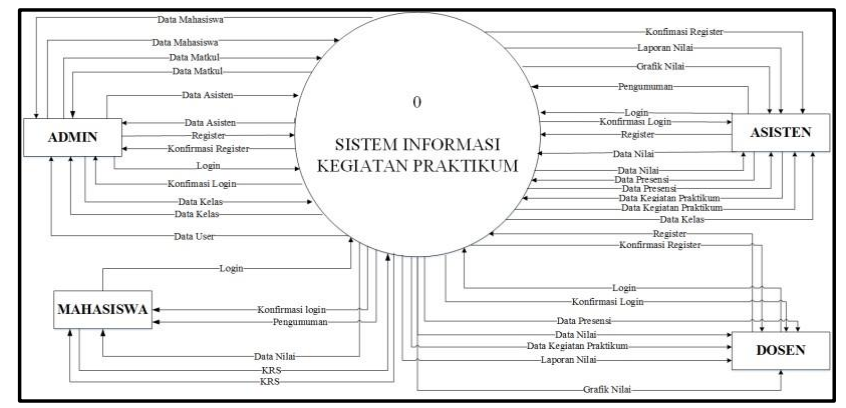

Gambar 2. DFD Level 0

\subsubsection{DFD Level 1}

Pada DFD level satu terdapat enam proses, yaitu register, login, admin, asisten, dosen, dan mahasiswa. Berikut adalah penjabaran dari masing-masing proses: 1) Proses register, pada proses ini terdapat satu output dan satu input. Admin, asisten maupun dosen melakukan register terlebih dahulu jika belum memiliki akun. Setelah melakukan registrasi maka akan muncul konfirmasi registrasi ke masing-masing entitas. 2) Proses login, pada proses ini admin, asisten, mahasiswa maupun dosen melakukan login. Sistem akan melakukan pembacaan data, apakah data yang inputkan cocok dengan data yang ada pada database. Kemudian, sistem akan menampilkan konfirmasi login dan jika berhasil dapat langsung masuk ke sistem. 3) Proses admin, pada proses menjelaskan data apa saja yang keluar dan masuk pada bagian admin. Data yang masuk dan keluar terdiri dari data mahasiswa yang tersimpan pada data storage mahasiswa, kemudian data asisten yang tersimpan pada data storage asisten, data kelas dan data matkul yang tersimpan pada data storage kelas dan matkul. 4) Proses asisten, 
pada proses menjelaskan data apa saja yang keluar dan masuk pada bagian asisten. Data yang masuk keluar adalah data nilai yang tersimpan pada storage nilai, data presensi yang tersimpan pada storage presensi, data kegiatan praktikum yang tersimpan pada storage kegiatan, pengumuman. Proses ini juga asisten melihat laporan dan grafik. 5) Proses dosen, pada proses menjelaskan data apa saja yang keluar dan masuk pada bagian asisten. Data yang keluar adalah data nilai, data presensi, data kegiatan praktikum. Proses ini juga dosen melihat laporan dan grafik. 6) Proses mahasiswa, pada proses menjelaskan data apa saja yang keluar dan masuk pada bagian mahasiswa. Data yang masuk dan keluar yaitu KRS yang tersimpan di storage praktikum, data yang keluar adalah pengumuman dan nilai.

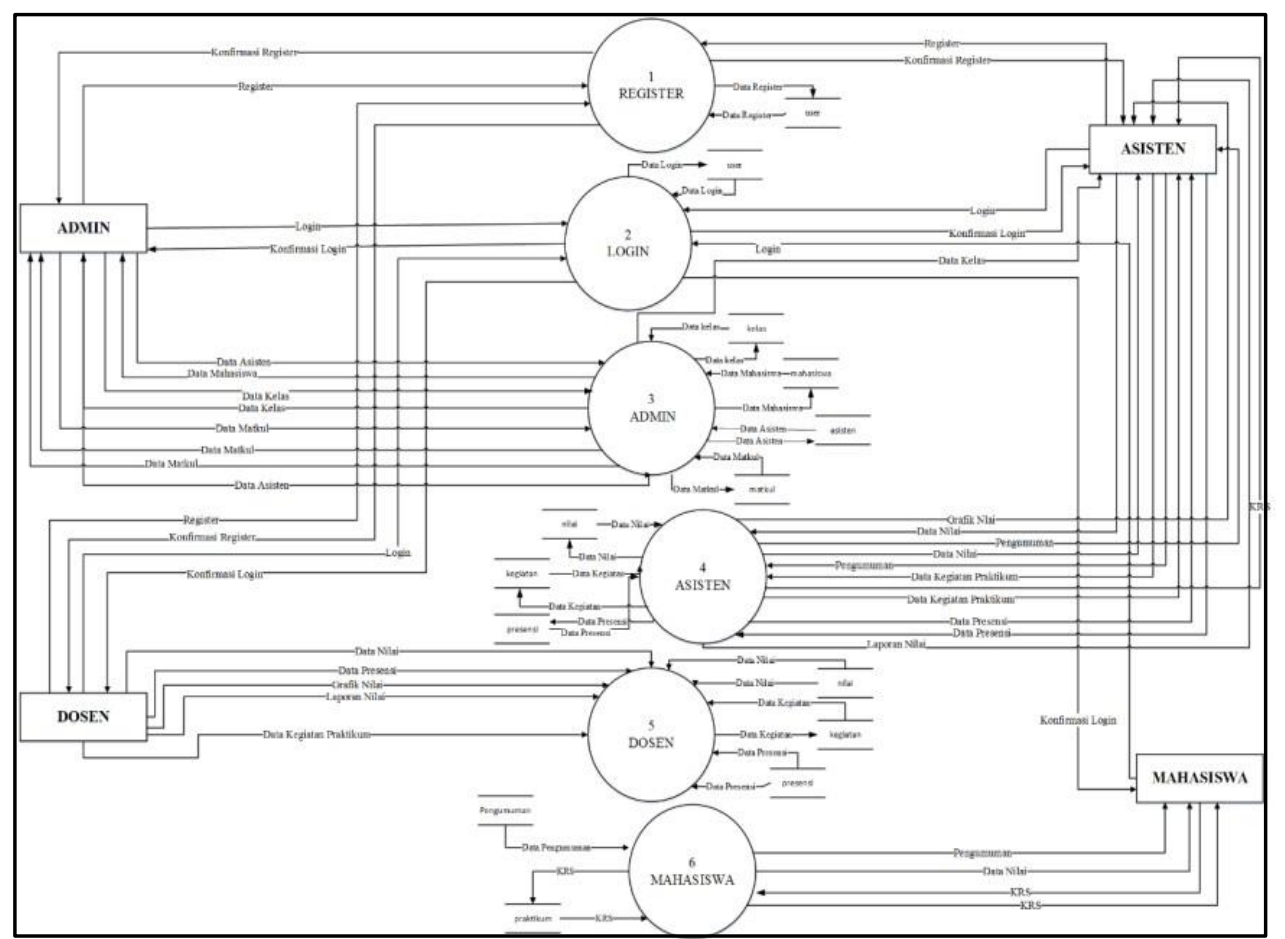

Gambar 3. DFD Level 1

\subsubsection{DFD Level 2 Proses 3}

Pada DFD level 2 proses 3 menjelaskan kegiatan yang lakukan oleh admin, terdapat empat proses lagi pada admin, yakni proses 3. 1 kelola data mahasiswa, data mahasiswa dilakukan dengan mengimpor data excel kemudian dibaca oleh sistem. Proses 3.2 kelola asisten, admin melakukan input data asisten, edit, hapus dan baca data. Proses 3.3 kelola data matkul, admin melakukan import data matkul dalam bentuk excel kemudian dibaca oleh sistem. Pada proses 3.4 kelola data kelas, admin melakukan impor data kelas yang dibaca oleh sistem.

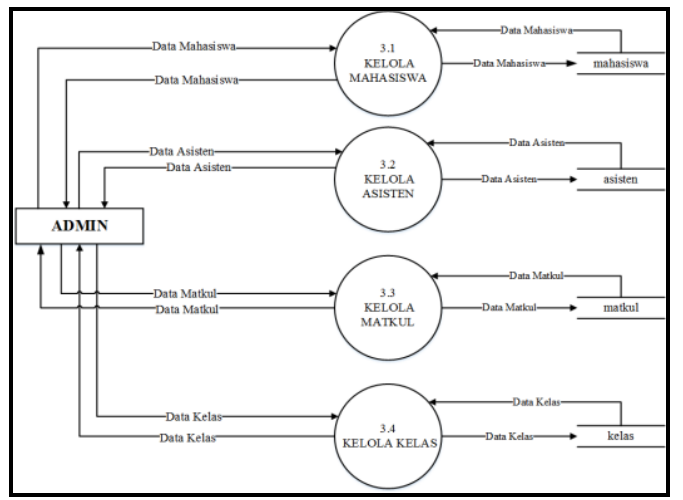

Gambar 4. DFD Level 2 Proses 3 
3.3 Perancangan Basis Data

Perancangan basis data pada sistem informasi ini digunakan untuk memenuhi kebutuhan akan informasi dari pengguna dan aplikasi yang digunakan dan menyediakan struktur informasi yang natural dan mudah di mengerti oleh pengguna. Pada perancangan basis data, terdapat struktur tabel, diagram hubungan entitas dan relasi antar tabel.

\subsubsection{ERD (Entity Relationship Diagram)}

Perancangan Entity Relantionship Diagram atau ERD adalah ilustrasi dari entitas-entitas dan hubungan antar entitas. Tujuannya, menunjukkan struktur objek data (entity) dan hubungan (relantionship) yang ada pada objek.

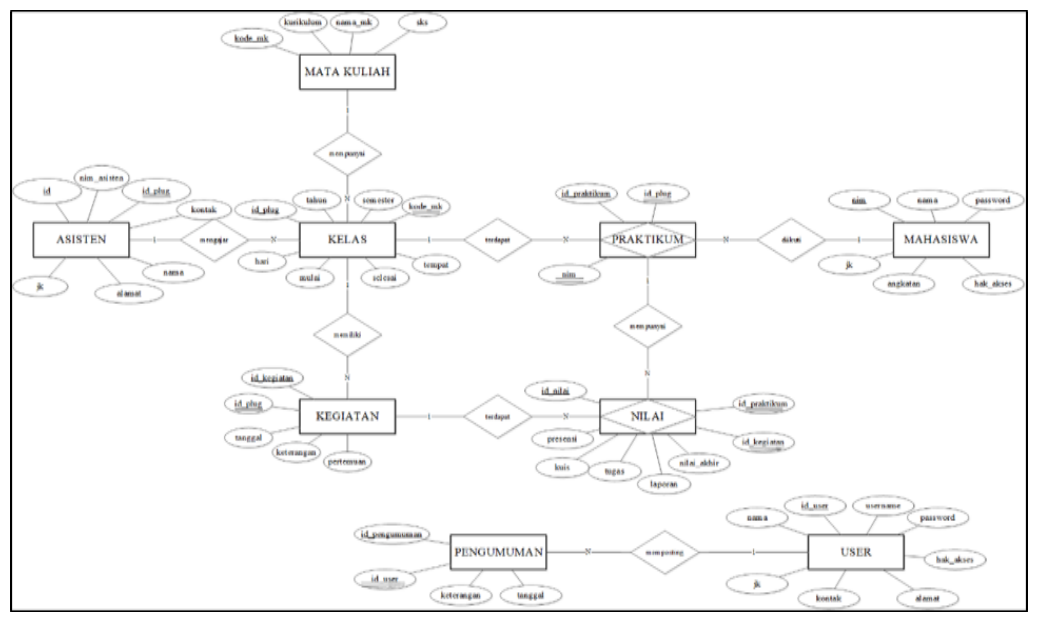

Gambar 5. Entity Relantionship Diagram (ERD)

\section{HASIL DAN PEMBAHASAN}

\subsection{Halaman Sistem Pemantauan Kegiatan Laboratorium}

Pada halaman lihat nilai praktikum dan input nilai, asisten dapat menginputkan dan mengetahui informasi nilai mahasiswa (lihat gambar 6). Nilai terdiri dari nilai kuis, nilai tugas, nilai laporan, nilai projek dan nilai responsi.

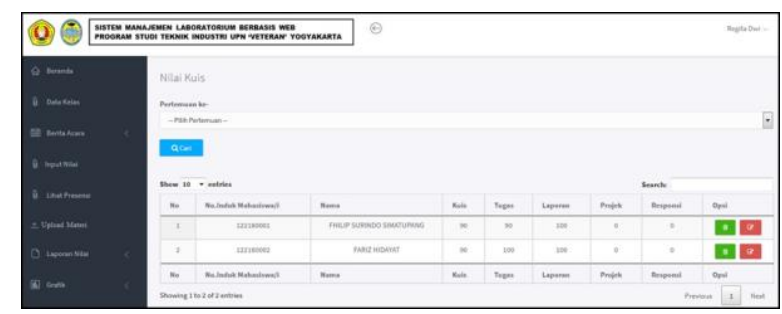

Gambar 6. Halaman Lihat Nilai

Pada halaman presensi, asisten dapat mengetahui informasi presensi mahasiswa di setiap pertemuan praktikum, terdapat fasilitas filter data menampilkan presensi berdasarkan pertemuan (lihat gambar 7). 


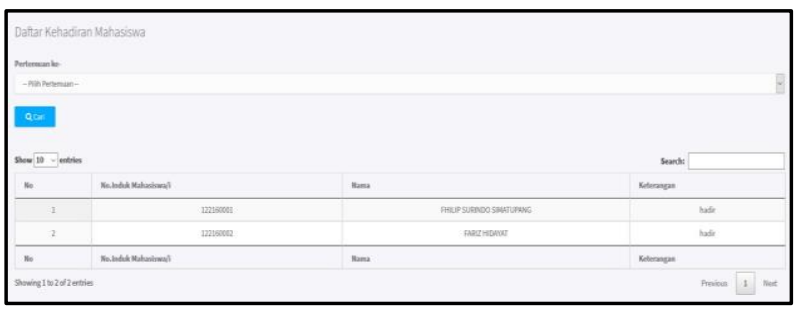

Gambar 7. Halaman Presensi

Pada halaman grafik nilai terdapat dua jenias grafik yakni menampilkan grafik perkembangan nilai mahasiswa di setiap praktikum dan grafik jumlah keselurahan mahasiswa berdasarkan nilai akhir di setiap kelas (lihat Gambar 8).

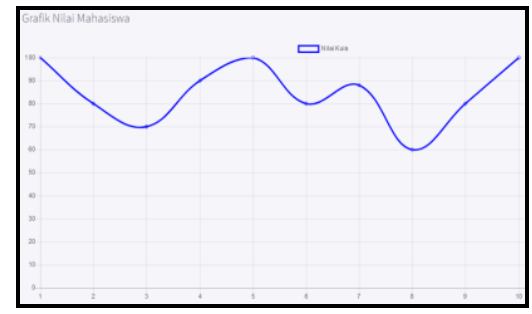

Gambar 8. Halaman Grafik Nilai Mahasiswa

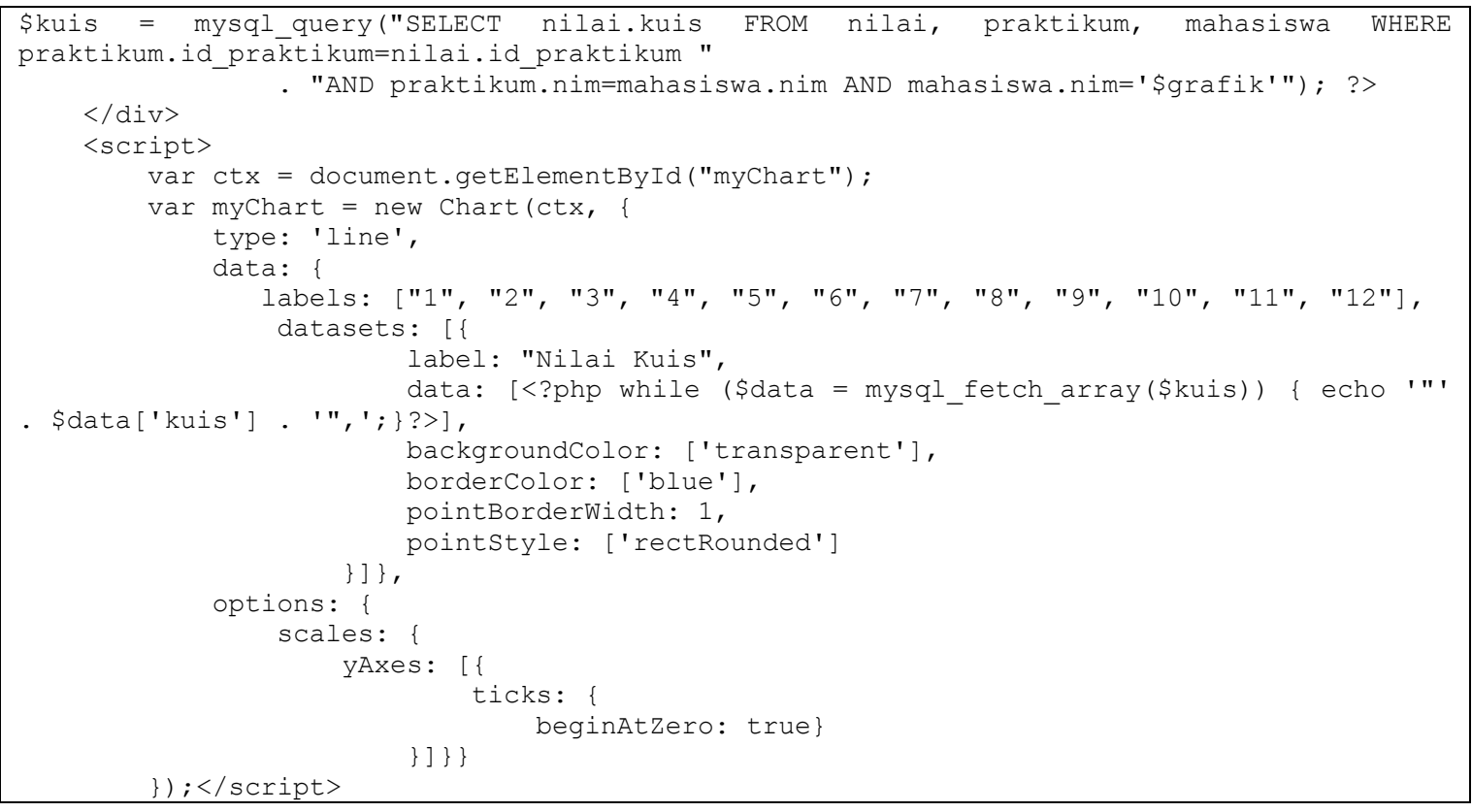

\section{Modul Program 1. Pseudocode Halaman Grafik Mahasiswa}

Pada halaman laporan nilai bertujuan memberikan informasi kepada asisten mengenai hasil kalkulasi dari nilai-nilai kegiatan dari awal pertemuan sampai responsi (lihat gambar 9). 


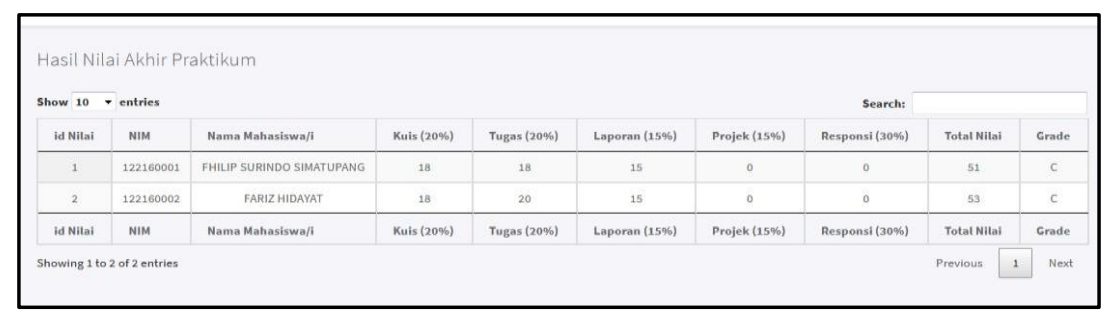

Gambar 9. Halaman Laporan Nilai Akhir

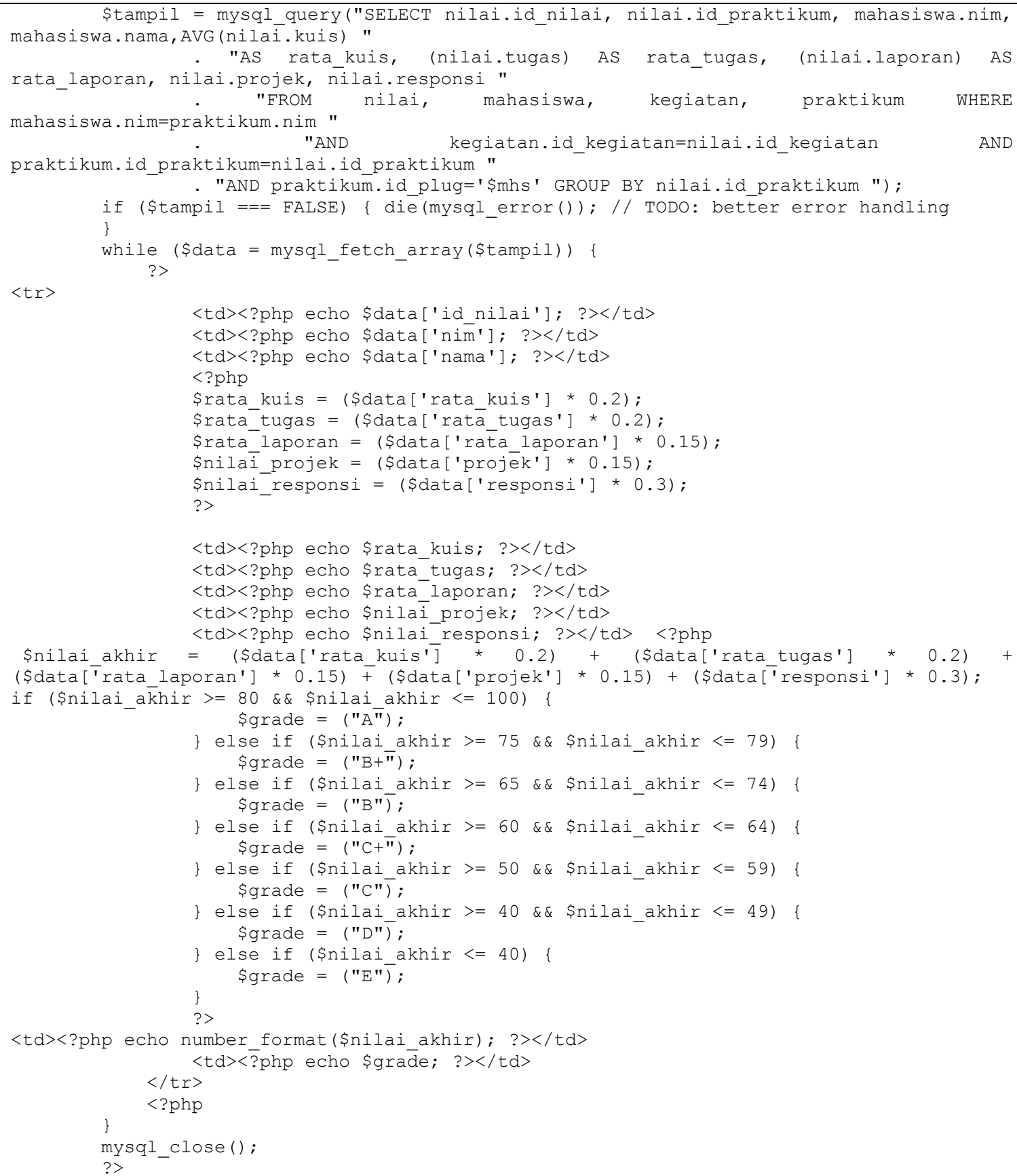

Modul Program 2. Pseudocode Halaman Laporan Nilai 


\section{KESIMPULAN}

Sistem berjalan dengan baik pada lingkungan laboratorium yang dapat mengelola data penilaian praktikum dan memberikan informasi kepada pengguna sistem, berupa rekap penilaian yang terdiri dari rata - rata nilai, jumlah nilai, dan konversi nilai ke dalam bentuk huruf sedangkan pemantauan nilai berupa grafik garis berdasarkan nilai di setiap pertemuannya dengan kategori nilai yang berbeda, yaitu nilai kuis, nilai tugas dan nilai laporan, untuk grafik batang berdasarkan jumlah mahasiswa di akhir praktikum sesuai dengan masing - masing plug.

\section{DAFTAR PUSTAKA}

Alammary, A., Carbone, A., \& Sheard, J. (2012). Implementation of a smart lab for teachers of novice programmers. In Proceedings of the Fourteenth Australasian Computing Education Conference-Volume 123 (hal. 121-130). Australian Computer Society, Inc.

Alghamdi, A., \& Shetty, S. (2016). Survey toward a smart campus using the internet of things. In Future Internet of Things and Cloud (FiCloud), 2016 IEEE 4th International Conference on (hal. 235-239). IEEE.

Arif, M. (2016, Maret 21). PENGEMBANGAN SISTEM INFORMASI PRAKTIKUM LABORATORIUM JARINGAN KOMPUTER TEKNIK ELEKTRO

[Skripsi.Theses.Dissertations]. Diambil 25 September 2018, dari http://etd.unsyiah.ac.id/index.php?p=show_detail\&id=20152

Cordiaz, M. (2017). Penerapan Smart Campus sebagai Pendukung Kegiatan Pendidikan dalam Tri Dharma Perguruan Tinggi. Jurnal Informatika Universitas Pamulang, 2(2), 77-80.

Diah, M. (2015). Makalah manajemen laboratorium. Diambil dari https://www.academia.edu/19090431/Makalah_manajemen_laboratorium

Indonesia, G. T. (2017, November 2). Definisi Smart campus. Diambil 3 Oktober 2018, dari http://smartcampus.co.id/artikel/32-definisi-smart-campus

Santosa, P. S. (2017). PENGELOLAAN LABORATORIUM DI PERGURUAN TINGGI. MAJALAH ILMIAH BAHARI JOGJA, 15(25), 1-18.

Setiawan, T. D. (2012). Pengembangan Sistem Informasi Manajemen Laboratorium Teknik Mekanik Otomotif Pada Smk Berbasis Database Microsoft Access. Teknologi dan Kejuruan, 32(1).

Sulistyo, W., Suyanto, B., Yudantoro, T. R., \& Yulianto, T. (2013). PEMANFAATAN ELEARNING SEBAGAI PENDUKUNG PROGRAM POLINES SMARTCAMPUS. Jurnal Informatika, 5(2), 531-541.

Sulistyohati, A., Kusumawardani, S. S., \& Santosa, P. I. (2017). KAJIAN INDIKATOR PENGUKURAN KESIAPAN PADA GREEN SMART CAMPUS MENGGUNAKAN KERANGKA KERJA GREEN IT READINESS+. Prosiding Semnastek.

Susanti, N., \& Arifin, M. (2012). Sistem Informasi Manajemen Laboratorium (SIMLAB)(Studi Kasus Laboratorium Progdi Sistem Informasi UMK). Majalah IImiah INFORMATIKA, 3(1).

Suyanta. (2010). MANAJEMEN OPERASIONAL LABORATORIUM.

Utama, Y. (2011). Sistem Informasi Berbasis Web Jurusan Sistem Informasi Fakultas IImu Komputer Universitas Sriwijaya. Jurnal Sistem Informasi, 3(2). 